\title{
Introduction on One Calligraphic Criteria Based on Early Theory \\ Books--Vertical and Horizontal Strokes with Imagery
}

\author{
Luan Yipeng \\ Weinan Normal University,Weinan Shanxi Province 714000,China
}

\begin{abstract}
Keywords: Calligraphy; Vertical and horizontal strokes with imagery; the cursive script; psychological needs
\end{abstract}

\begin{abstract}
Vertical and horizontal strokes with imagery, the first calligraphic criterion since the end of the Han Dynasty, refers to the associative imagery from the combinational relations among calligraphic strokes. Its establishment benefited from the perfection of the cursive script and was then applied to all calligraphy fonts. The imagery, which is from a very wide range of sources, can describe all aspects of calligraphy. Meanwhile, it is also some kind of psychological needs.
\end{abstract}

\section{Introduction}

As the criteria for calligraphic merits, vertical and horizontal strokes with imagery appeared in the early theory books during the early period of the Six Dynasties, which seemed to become the mainstream way to evaluate calligraphy at that time. Although this kind of evaluative method still exists in the later calligraphy, it often appeared in a transformative or hidden way because of the integration of other evaluation criteria, which made it less obvious in the early theory books. Therefore, choosing the early theory books as the grounding for the study of this calligraphy evaluation criterion will make it clearer.

First of all, it needs to be pointed out that in most theory books and calligraphic works, the imagery in vertical and horizontal strokes with imagery is not real images or images that can be directly perceived in painting, sculpture and other artistic works but a virtual image or a mental image obtained from the calligraphic works through psychological activities such as imagination by the creator or the viewer. The condition under which those virtual images are generated is the meaningful connection and combination of many strokes that are rich in texture. Because of the great development of the writing since the end of the Han Dynasty and the great abundance of the stroke combination brought by the widespread use of paper in the calligraphy, either the creator or the viewer can feel the real existence of imagery. This not only gave birth to the climax of calligraphy creation, but also consolidated the establishment of vertical and horizontal strokes with imagery as one evaluation criteria.

\section{The Second Pictographic Period of Calligraphy Brought by the Cursive Script}

The first pictographic period of calligraphy emerges as a way of creating characters at its beginning period, which was also the first way to create characters. It is easy to identify the existence of this pictograph in the early writings scribbled on the oracle bones, bronze objects and so on.

As is known to all, instead of ending up in the alphabet, Chinese character changes constantly on the basis of the original hieroglyphics. At the stage of clerical script, its pictographic elements on 
the surface have disappeared, replaced by abstract strokes. However, pictographic genes in the characters are not lost but hidden and transformed into an inconspicuous level, waiting for a suitable opportunity to appear in a face-lift way.

The great development of the cursive script gave them the opportunity. As a saying goes, the cursive script appeared as the Han Dynasty flourished. From its beginning to the end of the Han Dynasty, when Zhang Zhi and others were the cursive calligraphers, the cursive script has experienced hundreds of years of evolution, widespread application of and writing skills have reached a peak period.

What differentiates the cursive script from other standardized forms such as seal, clerical and regular scripts is that the gesture of the cursive script always seems in movement, which creates infinite possibilities in the connection of the strokes and produces an unexpected image. This kind of "imagery" is different from the pictograph at the beginning stages, as there is almost no concreteness but only abstract elements revealed in the texture and the combination of strokes to produce some kind of indefinite association. But it is just because of its uncertainty that the second "pictographic" period of this calligraphy obtained a larger degree of freedom and unlimited possibilities, so that the cursive script was able to present natural things, extraordinary abilities of heaven and earth and that so many cursive calligraphers and appreciators could reach to almost crazy situation. Having been absorbed in learning cursive, they studies hard, looked for new heights and forgot about fatigue. It was already rather late, they still reminded themselves not to rest; the sun is to the west but they had no time for lunch. For every ten days averagely each of them would wear out a brush pen; for a month, they would use up numbers of ink pills. Their collars and sleeves looked like ink; lips and teeth were often black; even if they got together, there was no time for talking or playing; they were busy drawing with fingers on the ground or scraping on the wall with cursive, so that their arms were excoriated and fingernails broken or even bleeding. But they refused to stop and rest.[1]

At that time, calligraphers would not begrudge to using the most beautiful language to describe the new pictograms obtained by the cursive script, which often involved the comparison with the first hieroglyphics of calligraphy.

“......It is just like beasts standing on tiptoes and birds lifting its body, wanting to fly away, or a cunning rabbit suddenly frightened, wanting to run away......”[2]

"For the shape of the cursive, it looks like the moon in the sky, which is radiant and enchanting, curved and powerful; strokes are jointing together, handsome and charming; it also looks like a rare phoenix, stretching wings for fly, with dynamic embodied in stillness; it is still like mollusc snakes winding and tortuous.. . It seems as gentle breeze blowing young trees, swinging and waving in a harmonious and smooth state.”[3]

The various natural things in these associations are developed around the word "gesture", which is the dynamic shape of all natural things or the dazzling impression left on people seeing a certain scene. That is the remarkable difference between the second pictographic period initiated by the cursive script and the first pictographic period with static recognition. This difference is directly related with the speed of writing, the echoing prominence and the increase in gesture richness that are applied in the cursive script.

Since then, people took a different light in the writing of words, or we could say that writing at this time gained an independent position from purely practical uses. People began to create characters for aesthetic purposes and for the appreciation of writing, and writing for the first time became an art of calligraphy. Also for the first time there appeared a crazy group that took delight in calligraphy, which is described in "Non-Cursive". 


\section{The Source of Imagery in Vertical and Horizontal Strokes and Its Describing Objects}

The source of imagery in vertical and horizontal strokes in early book theories is very broad, raging from heaven and earth, natural and artificial things, mythology and reality to external and internal things, almost including everything. One can see whatever that can make people feel empathy, beauty, amazement or things that are magical and dynamic and so forth.

Yang Quan once wrote "Ode on the Cursive Script" in the Wei and Jin Dynasties. Although it is short, it involves a lot of species, which can be cited as an example

"Among all the six fonts, the cursive script is considered to be the most miraculous. It is just like willows blown by the wind or gracefully moving dragons. It is reflective of oracles of divinities and the changing shape of the moon and the sun. The characters in the cursive script are upright, balanced and flat. Sometimes it seems restrictive and inclusive, but sometimes it seems wild and drooping. Some are written in order but some are out of order. Some are as high as mountains and some are protruded as bamboo shoots. That beautiful random strokes looks like bright pearls as well as spring willow branches. That stretched writings and features seem like slender eyebrows of beauties. The smoothness and moisture is like falling water from the eaves. The sturdy stroke bones are the same as the broad column base. That accuracy and insight as if skilled craftsmen have tried every trick. That showy display as if deadwoods are covered with frost and snow. Countless skillful gestures are full of wonders! That tactful and winding strokes is like silkworms making silks, endless and continuous. "'[4]

Involved plants are: willows, bamboo shoots, spring flowers

Involved animals are: dragons, phoenixes

Involved people are: beauties, maids

Involved natural scenes are: the sun and the moon, mountains, raindrops, freezing frosts

Involved daily articles are: pearls, plinths, silks

Involved events: craftsmen's spirit

Most of the objects above are associated with their corresponding actions to show its dynamic. There are some other movements with no subjects, such as "upright”, "balanced”, “inclusive”, "drooping”, "out of order".

The dynamic objects above are used to describe the font - the cursive script. Similar theory books include Cui Yuan's Gestures of the Cursive Script mentioned above, Suo Jing's Gestures of the Cursive Script and Xiao Yan's Shapes of the Cursive Script and so on. In addition, for other fonts, there are similar works, such as Cheng Gongsui's The Clerical Script, Cai Yong's Gestures of the Seal Script, Wei Heng's Gestures of Ancient Characters and Gestures of the Cursive Script and so on, which took roughly the same scope of describing objects as the cursive script, focused on one single font.

It can be seen that the describing objects of vertical and horizontal strokes with imagery are dominated by fonts with some descriptions about the use of brush pen and specific strokes as well as personal style, discussed respectively as following.

"Ode on the Use of Brush Pens" is said to have been written by Wang Xizhi, in which a large number of metaphors are used to deliver excellence of the use of brush pens. “......The brushstroke of the cursive script seems to be interrupted but instead connected, just as dragons and phoenixes live together, indisputable. While writing, the hair seems to point to the crown cap and eyeballs seem to be particularly protruded, as if holding weapons and going to the battles with full loyalty. Suddenly he suddenly waves his brush pen to write with black and white split on the paper but at 
the same time crossing through each other, becoming a clan. It resembles the sky clouds and the valley pine trees......"[5]

This article can be seen as a representative work to describe the use of brush pens in ways of vertical and horizontal strokes with imagery.

In addition, there are specific descriptions of the concrete stroke imagery which was carried forward by later generations to generate many graphic remarks. Represented by "The Eight Principles of Yong", remarks that appeared in the early theory books include the following:

There are following words in "Study on Strokes", which is said to have be written by Madame Wei:

"Horizontals are like miles of clouds, indistinct but of actual shape.

Dots are like stones falling from high mountains.

Left-fallings are like swords breaking apart the ivory.

Hooks are like hundreds of bows and arrows, waiting to be shot away.

Verticals are like withered rattans of thousands of years old.

......”[6]

There are descriptions in "chapter four: study on dots” in the book Twelve Chapters of Study on Strokes which is said to have been written by Wang Xizhi. "Writing points demands a magnificent momentum, like a stone blocking the way on the road, or like a squatting kite or a tadpole or a melon....." [7] In chapter five, there are words going like this: "Writing the stroke Ge demands a dignified and solemn posture. This stroke is like a tall pine hanging on the valley as if to fall down, but it is also like a bow just opened......”[8]

To describe the style of calligraphers in ways of vertical and horizontal strokes with imagery came a little later. In the representative work, Xiao Yan's Merits and Faults of Ancient and Modern Bookman, it said,“calligraphy of Zhong You is like swans flying in the clouds, sea swallows playing in the waves. The overtone of writing looks like luxuriant vegetations, which is far beyond our reach. Calligraphy of Wang Xizhi is vigorous and elegant, as if dragons jump over the heavenly gate and tigers lie in the Phoenix Palace. So people of all ages treasured his calligraphy and regarded it as the benchmark of calligraphy. Calligraphy of Wei Dan has the power of dragons and verve of tigers, looking like an unsheathed sword or an arrow on the bowstring. The handwriting of Zhang Zhi seems as the sendoh love by Emperor Wu of Western Han, dreamy and incredible. The handwriting of Xiao Ziyun is like a solitary old pine on the cliff as sky peaks cover the sun; and also like Jing Ke bearing a sword, or warriors bending bows or hunters hunting tigers....”[9]

It should be noted that remarks of this period of were focused on the calligraphic works themselves either in terms of fonts, the use of brush pens, strokes or styles, and thereby truly expressing the images that creators have in their mind during the process of creation and the associations brought by the works to appreciators. This is essentially different from the later metaphors with some kind of appropriateness of courtesy.

\section{Vertical and Horizontal Strokes with Imagery as a Psychological Need}

\section{Relax oneself.}

In "Theory on Brush Pens", Cai Yong directly points out the psychological state demanded by the creation of calligraphy: "To write is to relax oneself. Before writing, one must remove all the burdens and then write casually." [10]This state of mind is not so much a need to create calligraphy as an ideal state that calligraphers seek through the creation of calligraphy. He goes on to say: "To write well, we must sit silently and think casually. Don’t talk. Be calm, serious and respective as if 
in face of the supreme power.....” [11]This is completely isolated from the earth, as if going into another world. Then what's in this world? He continues to say: "The gestures of characters must be in line with a certain image, such as walking, flying, moving, coming, going, lying, getting up, worrying or exciting. It is like insects eating leaves. It is like sharp swords and rigid bows and arrows. It is like fire and water, clouds and fog, the sun and the moon. Only strokes that are reflective of imageries can be called calligraphic art."[12] He continuously uses 16 metaphors raging from body gestures to natural things and ends up in pointing out the theme that only strokes that are reflective of imageries can be called calligraphic art. This is of great significance as it is the first time in the history of calligraphy to have made clear the proposition of vertical and horizontal strokes with imagery. What matters more is what calligraphers can get through writing in vertical and horizontal strokes with imagery. Cai Yong doesn't make it clear, but we can follow his ideas. Everything in the external world at this time has been put aside and the calligrapher goes into a different world with various imageries. He is obsessed with this new world, hanging around, totally immersed in the pride and joy of being the creator. With secular things swept away, the calligrapher is detached from and placed over the sight of ordinary people, obtaining great mental satisfaction.

\section{Seek nature}

Since the Wei and Jin Dynasties, metaphysics sprung up with the decline of Confucian classics of the Han Dynasty and the absurd combination of theology with the Confucian school was removed from the stage of history. As metaphysics is a mixture of Confucianism and Taoism, the tendency of advocating nature in Taoism has become one of the characteristics of metaphysics, which has greatly influenced the thought of scholars since the Wei and Jin dynasties.

Landscape poetry prevails and landscape painting prospers. In Zong Bing's "Preface on Landscape Painting", he wrote: "Saints look at everything with truth and sages experience everything with an inclusive attitude. As for natural landscapes, they are specific and interesting...... Saints and sages discover and comprehend natural rules which are reflected by the landscapes, so that wise people take delight in travelling around the mountains and rivers to obtain the truth. Isn't it?"[13]He believes that all kinds of natural things enable people to comprehend the truth on the condition that one must make his own mind clear. This is no difference from Cai Yong's words that we should be calm, serious and respective as if in face of the supreme power.

But calligraphy, after all, is not poetry and painting. Poetry can describe its objects directly through words. The same goes for painting, which is able to draw out the shape of its objects. How about calligraphy? Where is the image? It seems like an empty world.

As Lao Tzu said , "Dao, vaguely and fuzzily, but there are images and entities” Wang Bi, the representative of metaphysics said, " Specific things all have their own rules. Only "Wu" (nothing) is the foundation of all things on earth. Only returning to "Wu" can they keep themselves intact.

Of course, Lao Tzu and Wang Bi were not talking about calligraphy, but strangely, their words accidentally reveal the characteristics of calligraphy - everything from nothing.

Although there is no specific shape of objects in the abstract combination of strokes, but it can arouse infinite associations of natural things through exquisite use of brush pens and "a continuous brushstroke". Being close to nature through calligraphy is one of the psychological factors leading to people's obsession with calligraphy at that time. 


\section{References}

[1].Zhao Yi. "Non-Cursive"[C]. On the Selection of Ancient Calligraphy. Shanghai: Shanghai Painting and Calligraphy Publishing House, 1979:2

[2].Wei Heng. "Study on Four Fonts" [C]. Sequel on the Selection of Ancient Calligraphy. Shanghai: Shanghai Painting and Calligraphy Publishing House, 1979:16

[3]. Suo Jing. "Gestures of the Cursive Script" [C]. On the Selection of Ancient Calligraphy. Shanghai: Shanghai Painting and Calligraphy Publishing House, 1979:19

[4]. Yang Quan. “Ode on the Cursive Script” [C]. On the Selection of Ancient Calligraphy. Cui Erping Shanghai: Shanghai Painting and Calligraphy Publishing House, 1993:17

[5].Wang Xizhi. "Ode on the Use of Brush Pens” [C]. On the Selection of Ancient Calligraphy. Shanghai: Shanghai Painting and Calligraphy Publishing House, 1979:36

[6]. Wei Shuo. "Study on Strokes” [C]. Sequel on the Selection of Ancient Calligraphy. Shanghai: Shanghai Painting and Calligraphy Publishing House, 1979:22

[7]. Wang Xizhi. Twelve Chapters of Study on Strokes[On the Selection of Ancient Calligraphy. Cui Erping Shanghai: Shanghai Painting and Calligraphy Publishing House, 1979:32

[8]. Wang Xizhi. Twelve Chapters of Study on Strokes[On the Selection of Ancient Calligraphy. Cui Erping Shanghai: Shanghai Painting and Calligraphy Publishing House, 1979:32

[9] Xiao Yan. Merits and Faults of Ancient and Modern Bookman [C]. On the Selection of Ancient Calligraphy. Shanghai: Shanghai Painting and Calligraphy Publishing House, 1979:81

[10]. Cai Yong. "Study on the Brush Pens” [C]. On the Selection of Ancient Calligraphy. Shanghai: Shanghai Painting and Calligraphy Publishing House, 1979:5

[11]. Cai Yong. "Study on the Brush Pens” [C]. On the Selection of Ancient Calligraphy. Shanghai: Shanghai Painting and Calligraphy Publishing House, 1979:6

[12]. Cai Yong. "Study on the Brush Pens” [C]. On the Selection of Ancient Calligraphy. Shanghai: Shanghai Painting and Calligraphy Publishing House, 1979:6

[13]. Zong Bing. "Preface on the Landscape Painting” [C]. Chinese Painting Series. Beijing: People 's Fine Arts Publishing House, 1985:1 